\title{
Qualidade da/na educação: narrativas de professoras sobre o trabalho docente
}

\author{
Maria Alfredo Moreira \\ Rosa Maria Moraes Anunciato \\ Maria Aparecida Pereira Viana
}

\section{Resumo}

Este artigo analisa textos escritos por 42 professoras em contextos de graduação, pós-graduação e extensão, com o objetivo de identificar concepções de qualidade da/na educação presentes em suas narrativas, produzidas em Portugal e no Brasil. Confrontamos as narrativas dominantes com a discussão do conceito de qualidade da/na educação associado a processos de transformação individual e coletiva que visam ao desenvolvimento de práticas democráticas e equitativas na escola, no trabalho docente e na sociedade. As narrativas das professoras mostram de que modo a qualidade da/na educação se associa ao trabalho docente como luta pela justiça social, quando procura valorizar e atender à diversidade e à inclusão de todos. Demonstram ainda como esse trabalho desafia as forças históricas e estruturais que condicionam a transformação da educação, procurando os fins democráticos que a educação escolar deve perseguir.

Palavras-chave: abordagem fenomenológica; compromisso social do professor; desenvolvimento profissional; inclusão educacional. 


\section{Abstract \\ Quality in/of education: teacher narratives on teacher work}

This research article analyses texts written by 42 teachers in graduate, postgraduate and outreach education programs, in order to identify within their narratives what they report as quality in/of education, in two national contexts: Portugal and Brazil. The prevailing narratives are confronted with the discussion of the concept of quality in/of education associated with processes of individual and collective transformation that aim at the development of democratic and equitable practices in school, within teaching work and in society. The teachers' narratives show how quality of/in education is associated with teacher's work to fight for social justice, when it seeks to value and attend to the diversity and inclusion of all. They also show how this work challenges the historical and structural forces that condition the transformation of education, seeking the democratic means that school education must pursue.

Keywords: educational inclusion; phenomenological approach; professional development; teacher social commitment.

\section{Resumen \\ Calidad de la/en la educación: narrativas de profesoras sobre el trabajo docente}

Este artículo analiza textos escritos por 42 profesoras en contextos de graduación, posgrado y extensión, con el objetivo de identificar concepciones de calidad de la/en la educación presentes en sus narrativas, producidas en Portugal y en Brasil. Confrontamos las narrativas dominantes con la discusión del concepto de calidad de la/en la educación juntamente con procesos de transformación individual y colectiva que apuntan al desarrollo de prácticas democráticas y equitativas en la escuela, en el trabajo docente y en la sociedad. Las narrativas de las profesoras muestran cómo la calidad de la/en la educación se asocia al trabajo docente como una lucha por la justicia social, cuando busca valorar y atender a la diversidad y a la inclusión de todos. También muestran cómo este trabajo desafía las fuerzas históricas y estructurales que condicionan la transformación de la educación, buscando los fines democráticos que la educación escolar debe perseguir.

Palabras clave: compromiso social del profesor; desarrollo profesional; enfoque fenomenológico; inclusión educativa. 


\section{Introdução}

Estamos vivendo a Agenda 2030 para o Desenvolvimento Sustentável da Organização das Nações Unidas (ONU), em vigor a partir de $1^{\circ}$ de janeiro de 2016. Os 17 Objetivos de Desenvolvimento Sustentável (ODS), desdobrados em 169 metas e aprovados por unanimidade pelos 193 estados membros, visam resolver as necessidades das pessoas, enfatizando que ninguém deve ser deixado para trás (Portugal. Comissão..., 2020). O ODS 4 incide exatamente sobre a educação de qualidade, entendida como inclusiva e equitativa em todos os níveis de escolaridade e para todas as pessoas, independentemente de sexo, idade, raça, etnia, incluindo pessoas com deficiência, migrantes, povos indígenas, crianças e jovens.

Numa sociedade cada vez mais desigual, o fosso entre os ricos e os pobres, bem como os níveis de pobreza e de exclusão social, são verdadeiras ameaças a essa Agenda, apesar dos avanços notáveis nos direitos humanos a que assistimos na transição do século (Torres Santomé, 2011). Continuamos a ter níveis de abandono e de insucesso escolar escandalosos em todo o mundo, principalmente no que diz respeito às crianças oriundas de classes trabalhadoras, de raças/etnias minoritárias e com antecedentes migratórios, em grande parte devido aos maiores riscos de exclusão social e de pobreza que experienciam (Kraszewska; Knauth; Thorogood, 2011; Torres Santomé, 2011).

Em todo o mundo, as dimensões pessoais, familiares, escolares, comunitárias e os fatores associados se convertem em práticas e discursos de exclusão, naturalizando o fracasso escolar e o abandono educativo como fenômenos inevitáveis. Essa naturalização é uma marca de políticas e movimentos darwinistas de natureza neoliberal e mercantilista que alimentam a criação de subjetividades nos "fracassados" e que os fazem acreditar que não se encaixam no sistema escolar (Vázquez Recio; López-Gil, 2018), em vez de perceberem que não são eles e elas que abandonam a escola, mas a escola é que os abandona (Freire, 1991).

A educação de qualidade para todas as crianças e jovens é um imperativo global de sustentabilidade das nações e do planeta. Dela depende não apenas a pujança da economia global, mas também o bem-estar e a qualidade de vida dos indivíduos. Uma educação de qualidade, associada ao sucesso acadêmico, é fundamental para a promoção da mobilidade social, na medida em que apenas a elevação do capital cultural, humano e social das populações lhes permite aceder a carreiras profissionais que rompam com ciclos de pobreza e de baixas aspirações, melhorando suas condições econômicas e sociais (OECD, 2011).

\section{Qualidade da/na educação: discutindo narrativas dominantes}

O conceito de qualidade da/na educação é um dos mais contestados socialmente e raramente se associa às desigualdades sociais, econômicas e culturais das populações. Se queremos assumir e defender o direito universal a uma educação de qualidade, não podemos deixar de submeter à análise crítica os discursos e as 
práticas que se produzem no campo (Escudero; Trillo, 2017). Torres Santomé (2006, p. 30) alerta-nos para a necessidade de desenvolvermos um posicionamento crítico, de análise dos discursos dos produtores de narrativas de qualidade e excelência, segundo os quais o mundo no qual vivemos pauta-se pela igualdade de oportunidades, não fazendo sentido relacionar classicismo, racismo, sexismo, injustiças e desigualdades sociais com o fracasso escolar; essas narrativas são legisladas e impostas como se tratassem de uma questão técnica e neutra. Como afirma Apple (apud Paraskeva, 2010), quando a educação é vista como transmissão de conhecimento neutro, seu papel é preparar os estudantes para a competição, ao mais baixo custo e o mais eficazmente possível.

A ideia de currículo neutro assenta numa concepção de conhecimento que valoriza claramente certas formas de conhecer em detrimento de outras - há apenas uma forma certa de conhecer, produzida histórica e culturalmente por uma estrutura herdada do colonialismo do passado, cujas ramificações se estendem ao presente (Quijano, 1992). Nas palavras de Santos (2008, p. 28), o (ainda) predomínio de uma perspectiva colonialista nas sociedades ocidentais constitui uma forma violenta de epistemicídio, um "fascismo epistemológico", que consiste em "uma relação violenta de destruição ou supressão de outros saberes". Essa hierarquia de saberes e conhecimentos na sociedade, trazida para a escola, resulta, muito frequentemente, na exclusão de determinados grupos sociais, habitualmente dos saberes e das experiências de minorias étnicas, rurais, com necessidades educativas especiais, de determinada orientação sexual ou religiosa. Essa exclusão constitui o que Paraskeva (2016) denuncia como "epistemicídios curriculares nas escolas", isto é, a supressão das formas de conhecimento nos currículos e nas salas de aula das comunidades e famílias das crianças e dos jovens pertencentes a grupos minoritários menos poderosos.

No caso português, podemos afirmar que as vozes mais ausentes são as das comunidades ciganas. Em Portugal, as crianças e os jovens de etnia cigana continuam a ser o grupo que mais apresenta retenções e abandono escolares (triplicam os valores para a restante população), que mal conclui o ensino secundário e quase não chega ao ensino superior (CE, 2012; Portugal. DGEEC, 2017). O crescente anticiganismo na Europa constitui a principal barreira à efetiva inclusão dessas comunidades, pois trata-se do grupo que corre maiores riscos de pobreza nos 28 países membros - 80\% versus $17 \%$ para a população geral (FRA, 2019). O país tem vindo a melhorar muito os índices de inclusão dessas populações, aumentando bastante o número de crianças na escola (Portugal. DGEEC, 2017), por meio de programas de mediação intercultural e de formação de professores. Contudo, ainda estamos longe da efetiva igualdade e integração desses estudantes na escola portuguesa, uma vez que as práticas escolares ainda se sustentam em processos de assimilação cultural e não de efetiva integração, enquanto práticas educativas potenciadoras do sucesso dessas/es estudantes no currículo regular (Casa-Nova, 2013).

No caso brasileiro, registramos compromissos com o esforço contínuo de eliminação de desigualdades históricas, respeito pelos direitos humanos, pela 
sustentabilidade socioambiental, pela valorização da diversidade e da inclusão e pela valorização dos profissionais que atuam na educação de milhares de pessoas todos os dias (Brasil. MEC, 2014, p. 9). Esses princípios não perderam a validade e a pertinência ante a Agenda 2030 da ONU e deveriam ser incluídos como itens balizadores da qualidade na educação nas três etapas da educação básica, com particular atenção às seguintes modalidades:

- Educação especial - atende aos alunos com necessidades educacionais especiais, preferencialmente na rede regular de ensino, como sujeitos de direito ao acesso à escola. Apesar de, ao longo dos anos, esse coletivo ter ganho força e conquistado direitos legais, ainda existem déficits quanto à garantia da inclusão das pessoas com deficiência na escola.

- Educação indígena - as políticas públicas nacionais para os povos indígenas no Brasil têm como referencial os direitos diferenciados garantidos pela Constituição da República Federativa do Brasil de 1988. Apesar do reconhecimento da autonomia indígena e da necessidade de políticas específicas e diferenciadas, ainda há poucos espaços para a participação dos povos indígenas na elaboração de políticas públicas educacionais.

- Cultura afro-brasileira e africana - as lutas dos movimentos negros promoveram algumas conquistas, como a criação da Lei nº 10.639/2003, que incluiu no currículo oficial da rede de ensino a obrigatoriedade da temática "história e cultura afro-brasileira e africana". Por meio dela, as instituições de ensino podem se munir de orientações, princípios e fundamentos para o planejamento e a execução do conteúdo afro-brasileiro e africano em sala de aula.

- Educação do campo - as lutas dos movimentos sociais do campo e educadores comprometidos com a educação em ambientes rurais ampliaram o debate sobre a quase inexistência de políticas de educação para essa área, numa situação de invisibilidade dessa população.

Apesar do reconhecimento legislativo dos direitos a uma educação de qualidade desses coletivos, a emergência de fenômenos como a privatização, o gerencialismo e a empresarialização das escolas portuguesas e brasileiras tem vindo a ameaçar um projeto mais democrático e pluralista da educação (Antunes; Peroni, 2017; Peroni; Caetano; Arelaro, 2019).

\section{As narrativas dos professores na proposta de uma educação de qualidade}

A docência é uma prática social que deve ser problematizada, compreendida, transformada, dialogada e construída nos significados que emergem das práticas de professores e estudantes. A docência não resulta somente da utilização de conhecimentos teóricos numa perspectiva aplicacionista; esses são também 
construídos e reconstruídos no movimento da prática docente (Wilson; Shulman; Richert, 1987). No exercício da docência, o professor produz os conhecimentos necessários à sua ação, revendo e reconstruindo a sua intervenção pedagógica, numa atitude crítico-reflexiva, criando formas de ser e de agir necessárias para o desenvolvimento pessoal, profissional e institucional que Mizukami (2004) caracteriza como o protagonismo dos professores.

O acesso às experiências e aos conhecimentos dos professores pode efetuarse pelo recurso às suas narrativas profissionais. Os professores conhecem a docência por meio de imagens, rituais, hábitos, ciclos, rotinas e ritmos que têm por base a própria experiência, traduzida nas histórias dos professores e das escolas (Clandinin; Connelly, 2011). A vida é constituída por aquilo que nos atravessa e pelas nossas próprias experiências, e passar pela experiência é sair transformado por ela: "o que acontece enquanto experiência só pode ser interpretado narrativamente. É na história de nossas vidas que os acontecimentos ganham uma ordem e um sentido" (Larrosa, 2004, p. 17).

As experiências vividas e narradas pelos professores desencadeiam e atribuem novos sentidos ao vivido, servindo para melhor compreender o processo de ensinar e dar sentido ao trabalho docente (Martins; Anunciato, 2018). Olhar para suas histórias de vida possibilita se distanciar dos acontecimentos experienciados e, assim, analisá-los e, quando preciso, ressignificá-los. Ao reconstruir suas trajetórias no diálogo consigo e com os outros, por meio das narrativas, descortina-se um espaço de aprendizagens, de formação e de investigação.

As narrativas permitem-nos compreender como os professores elaboram concepções sobre a educação ancoradas nas experiências de vida e formação como sujeitos imersos numa história, cultura, territorialidade etc., mas, em particular, ancoradas na relação com o outro: estudantes e suas famílias, pares e gestores da educação. Perceber essas narrativas como fonte de conhecimento sobre a docência exige estarmos mais presentes e atentos aos pormenores que permeiam a vida cotidiana, em especial a vida docente que demanda diariamente ação e interação humana.

A pesquisa narrativa na formação de professores cria um espaço para ampliar a sua voz, problematizar as relações de poder ao equacionar alternativas aos discursos e às práticas vigentes, desterritorializando a formação de professores de um modo que desafia as hegemonias positivistas e tecnorracionalistas na investigação educacional (Paraskeva, 2011). Ao contar suas histórias únicas, os professores criam uma multiplicidade de histórias de qualidade da/na educação, que, simultaneamente, os inspiram e os educam, mas também aos outros que as leem. É isso que veremos no estudo empírico que realizamos com professoras portuguesas e brasileiras.

\section{Abordagem metodológica do estudo}

Na pesquisa narrativa, "o estudo da experiência como história é, antes de mais, um modo de pensar a experiência. Usar a metodologia da pesquisa narrativa 
significa adotar uma visão particular da experiência enquanto fenómeno sob estudo" (Connelly; Clandinin, 2006, p. 477 - tradução nossa). Desse modo, como o objeto de estudo é o discurso oral ou escrito, as perspectivas de análise são hermenêuticas (Bolívar, 2012) e fenomenológicas (Flick, 2009). A abordagem fenomenológica foca o sentido construído pelas professoras sobre o que constitui qualidade da/na educação e o modo como a experiência vivida modela essas representações. Por outro lado, a perspectiva interpretativa e hermenêutica cria espaço para as singularidades e comunalidades das histórias narradas, integrando-as num todo unificado que visibiliza o fenômeno estudado (Bolívar, 2012). É importante reconhecer que as narrativas das professoras são histórica e socialmente situadas, desenvolvidas em tempos e espaços afetados por condições pessoais e sociais únicas, dado que o indivíduo se inscreve numa rede contextual complexa, na qual se jogam fatores de ordem histórica, política, social, cultural, econômica etc., que vão necessariamente ter impacto no modo como se vê a si mesmo e na relação com os outros (DeloryMomberger, 2012).

Para efeitos da redação deste estudo, selecionamos textos autobiográficos escritos por professoras portuguesas e brasileiras, em contextos de graduação, pósgraduação e extensão. Tendo sido produzidos com finalidades associadas ao desenvolvimento profissional docente, em modalidade presencial e on-line, as autoras recuperaram essas narrativas, lançando agora outro olhar sobre as representações de qualidade da/na educação que emergem. Selecionamos as narrativas de 11 professoras portuguesas e 31 professoras brasileiras, de 2016 a 2018. Em 2018, convidamos as participantes para uma entrevista com a finalidade de refletir sobre o significado da experiência de escrita das narrativas para o seu desenvolvimento profissional. Cinco acederam à entrevista, que foi realizada entre outubro de 2018 e janeiro de 2019, em modalidade presencial e on-line.

Na recolha dos textos e no decorrer das entrevistas, as professoras participantes foram informadas dos objetivos do estudo e do tratamento que seria dado à informação recolhida, e deram seu consentimento informado. Foi assegurado também que apenas as pesquisadoras conheceriam as identidades das professoras, usando, com essa finalidade, nomes fictícios nos testemunhos.

O corpus de análise foi submetido à análise temática teórica, tarefa que visa decompor um componente dos dados e que é guiada pelo interesse teórico ou analítico do investigador (Braun; Clarke, 2006, p. 84). O objetivo é identificar temas e ideias, padrões repetidos em textos que remetam para o conceito de qualidade da/na educação e que sempre estiveram lá, tecidos nas palavras explícitas e sentidos implícitos dos discursos. A questão que nos orientou na análise foi a seguinte: Qual(is) é/são o(s) significado(s) de uma educação de qualidade para essas professoras e que se reflete $(m)$ nas suas práticas?

Na resposta às questões foi seguida uma análise temática latente dos textos, como método para identificar, analisar e relatar padrões (temas), com base em uma perspectiva teórica que reconhece o papel dos indivíduos na atribuição de significados à sua experiência, em diálogo com o contexto social mais vasto e que influencia o modo como esses significados são construídos (Braun; Clarke, 2006). Procuramos, 
assim, ideias, pressupostos e conceptualizações de qualidade da/na educação, sem deixar de equacionar a sua inscrição num determinado contexto histórico-cultural. Retornar aos textos vários anos depois exigiu releitura, movimentos de ida e retorno, à medida que íamos tematizando, refinando e ressignificando temas e subtemas ou categorias (Viana, 2019). O resultado final encontra-se na Figura 1.

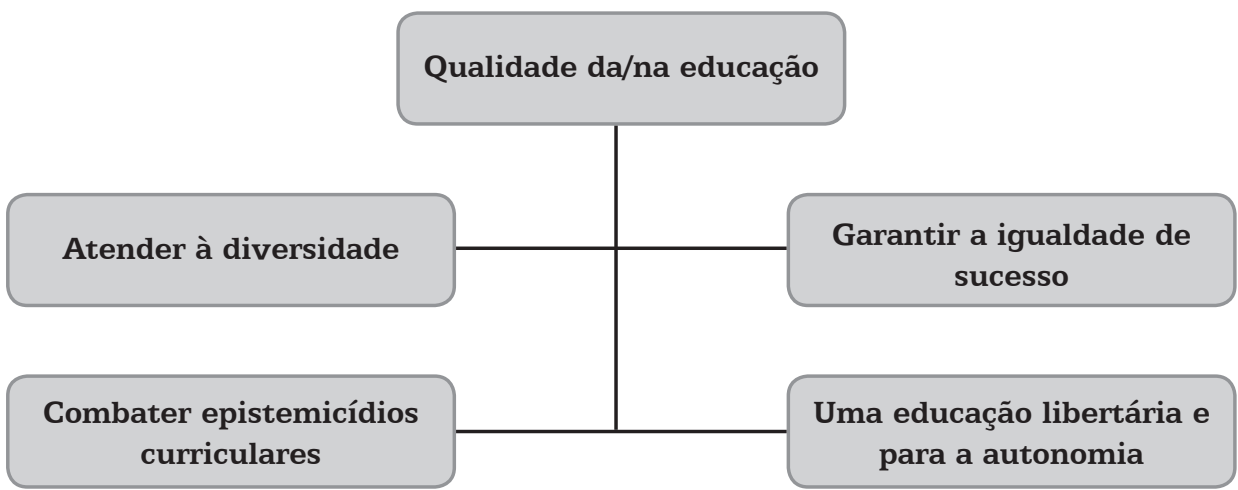

Figura 1 - A visão de qualidade da/na educação que emerge das narrativas Fonte: Elaboração própria.

\section{O que nos dizem as narrativas sobre qualidade da/na educação e seus constrangimentos}

A seguir, apresentam-se as categorias identificadas nas narrativas das professoras: atender à diversidade dos estudantes; garantir a igualdade de sucesso em sala de aula; combater os epistemicídios curriculares; e, educação libertária e para a autonomia.

\section{Qualidade da/na educação significa atender à diversidade dos estudantes}

Nas suas narrativas, que incidem nas suas práticas, e também naquelas que observam em outras colegas, as professoras sinalizam prioridades e dificuldades de um trabalho de sala de aula equitativo e inclusivo, antirracista e multicultural, que visa atender a cada estudante na sua especificidade, com particular atenção às crianças e aos jovens com necessidades educativas especiais.

O professor deve seguir uma abordagem metodológica com vista à equidade, envolvendo os estudantes num processo de construção de conhecimento que diminua o racismo e o preconceito. Este é um assunto importante nas escolas de hoje, pois o preconceito nunca foi tão elevado entre as crianças e os adolescentes com diferentes etnias, culturas, meios de origem e minorias. Às vezes esconde-se em pleno dia e nós, como professores, devemos conhecer todos os sinais. (Beatriz, professora portuguesa, narrativa, 2018).

Acima de tudo, é importante garantirmos que cada criança tem a oportunidade de estudar numa escola perto de casa (...) não devemos fechar escolas como estamos a fazer (...) as crianças com deficiência deveriam receber educação de 
acordo com a sua deficiência. Muitas vezes estão integradas na sala de aula, mas os professores sentem-se perdidos e não sabem o que fazer com elas. Estas crianças deveriam ser tratadas com respeito (...) os alunos deveriam ser vistos como indivíduos, não como números ou como mais um aluno. (Helena, professora portuguesa, narrativa, 2016).

Em seus escritos, essas professoras mostram que caminhos podem ser seguidos e que divergem do foco míope e acrítico em métodos fétiche (Bartolomé, 2007), guiando a decisão pedagógica por uma consciência sociopolítica e com atenção à heterogeneidade.

\begin{abstract}
A meu ver, o planejamento do trabalho com as crianças, a formação de duplas produtivas, a leitura constante, as atividades diferenciadas, a avaliação diagnóstica individual e o registro do desempenho de cada aluno, tudo isso foi bem pensado e organizado de forma a atender não só as necessidades da sala, mas também as especificidades de cada aluno, conforme as facilidades e dificuldades observadas. Isso demonstra o comprometimento da professora com uma educação de qualidade, que pensa no grupo ao dispensar um olhar individualizado sobre cada aluno, buscando atendê-los da melhor maneira possível, contribuindo com seu desenvolvimento e crescimento. (Simone, professora brasileira, narrativa, 2016).
\end{abstract}

\title{
Qualidade da/na educação significa garantir a igualdade de sucesso em sala de aula
}

Atender à diversidade dos estudantes, com vista à inclusão de todos num ambiente acolhedor, traz consigo uma prática de sala de aula centrada no aluno, histórica e contextualmente situada, que recupera e valoriza os saberes das comunidades de origem dos estudantes que são trazidos para a escola, sem deixar de existir uma instrução rigorosa e a aquisição de conhecimentos socialmente relevantes (Bartolomé, 2007; Darder, 2015).

\begin{abstract}
Nós conversávamos sobre direitos e deveres do cidadão, infelizmente num ambiente e para pessoas com os direitos pouco exercidos, pessoas com histórico de descaso, trabalhadores de serviços pesados, na lida do manejo da enxada, causa pelas quais as mãos dos alunos com idade mais avançada impedia de fazer uso do lápis com destreza. Tinha na parede o alfabeto, cartazes com as sílabas simples e as complexas e com os números. Mas o que mais importava para eles era aprender escrever e ler o nome e o sobrenome, cada aluno confeccionava seu crachá com seu nome, era muito importante saber com quais letras escreviam o próprio nome, era gratificante vê-los aprendendo a aprender. (Carolina, professora brasileira, narrativa, 2017).
\end{abstract}

O perfil dos alunos era bastante variado por ser uma multisseriada, vinham de ambientes não letrados em que a leitura e a escrita não tinham muito significado. Alguns estavam em idade avançada e ainda não estavam alfabetizados, mas ainda lembro dos seus olhos de confiança e esperança toda vez que eu iniciava as aulas, o que aumentava meu comprometimento e responsabilidade pela aprendizagem de cada um. (Josefina, professora brasileira, narrativa, 2017).

Em suas narrativas, as professoras desenvolvem uma consciência dos mecanismos de exclusão escolar que não as remete para um lugar de imobilismo e 
resignação; pelo contrário, essa consciência apenas reforça a assunção de uma responsabilidade social, um compromisso com o papel de proteção e defesa dos seus alunos.

\section{Qualidade da/na educação significa combater os epistemicídios curriculares}

Como Torres Santomé (2011, p. 524) nos recorda, é muito mais fácil distorcer os outros quando não somos capazes de ouvir suas vozes originais, seus argumentos, suas preocupações. Quando ouvimos as vozes dos professores e, por meio delas, as histórias dos seus alunos, percebemos de que modo as escolas estão populadas por histórias únicas sobre o outro, que excluem as vozes e as histórias de grupos minoritários (Adichie, 2009).

Em uma das turmas com qual trabalhei o livro "Menina bonita do laço de fita", as crianças não reagiram bem ao livro: falavam que a menina não era bonita, indicando vários preconceitos com relação ao que é ser negro ou negra no Brasil. Fui questionando as crianças sobre o que sabiam a respeito do continente africano, de onde os antepassados da menina do livro se originavam. As respostas indicaram ideias preconceituosas que são transmitidas pela mídia, inclusive. Após estudos e planejamento de atividades sobre o continente africano, pude mostrar outras imagens e ideias, o que pode contribuir para que algumas certezas fossem abaladas. (Elsa, professora brasileira, narrativa, 2016).

Lembro-me de uma aula de história do $9^{\circ}$ ano em que aprendíamos como Cristóvão Colombo chegou à América e como isso se tornou um dos maiores eventos mundiais. Lembro-me de me ensinarem que os nativos americanos não resistiram, na realidade, estavam curiosos acerca "dos homens brancos". Também me lembro de me ensinarem que os "homens brancos" não eram tão simpáticos para os nativos americanos. Os homens brancos trouxeram a morte com eles: violência, doença, escravatura, violação e pilhagem, até que os nativos fugiram das suas terras e se esconderam em lugares aos quais chamamos hoje reservas índias, pois as tribos nativas ficaram reduzidas a quase nada. O que acho triste é que durante estas lições de história nos ensinavam que as expedições europeias para a América eram essenciais, pois o "homem branco" tinha de trazer a civilização para os nativos (...) Este é apenas um exemplo de como a educação em Portugal está muito atrasada. Referi um grupo étnico que não está em Portugal, mas o que se passa com a população negra em Portugal? Ou com a população cigana? Estes certamente vivem no nosso país e não me lembro de uma só vez em que a sua cultura tenha sido referida e respeitada. (Sílvia, professora portuguesa, narrativa, 2018).

Para o combate aos epistemicídios curriculares presentes no cotidiano das escolas que sirva um projeto de educação de qualidade que desterritorialize o currículo e a formação de professores, Paraskeva $(2010,2016)$ propõe uma teoria curricular itinerante que nos obrigue a equacionar um pensar as alternativas de modo alternativo. Não se trata de substituir uma epistemologia por outra; trata-se de acolher e integrar a diversidade humana, a plenitude de uma ecologia de saberes que ultrapasse os abismos epistêmicos criados pelo colonialismo e que remetem determinados saberes para uma zona de invisibilidade e inexistência (Santos, 2007). Trata-se de promover uma educação verdadeiramente humana(ista). 


\section{Qualidade da/na educação significa uma educação libertária e para a autonomia}

Na perspectiva das professoras, o trabalho docente só adquire sentido se efetuado de forma reflexiva, enquadrado por uma visão da educação como espaço de transformação, promotor da autonomia do aluno e do professor, bem como da sua emancipação (Vieira, 2020). É no processo de construção da sua autonomia profissional, potenciado pela reflexão, que a escrita suscita, que vai se tornando cada vez mais evidente para essas professoras a necessidade de a fazer acompanhar pela autonomia do aprendente.

Em todas as reflexões que tenho realizado, estou sempre falando da prática docente (...) numa perspectiva de uma educação emancipatória/transformadora e uma visão de educação libertária. (Camila, professora brasileira, 2019, entrevista).

[Os meus objetivos são] estimular a autonomia do aluno, aprender a aprender, tomar consciência do seu processo de aprendizagem, ser o seu ator principal, incentivar o seu espírito crítico, a capacidade de trabalho de forma colaborativa e partilhada e a (co)construção de experiências, a pesquisa, desenvolver a tolerância e o respeito pela diversidade cultural. (Mariana, professora portuguesa, entrevista, 2018).

Assim se constrói, de forma dialética, um novo ou enriquecido conhecimento, uma práxis, compreendida como a estreita relação que se estabelece entre um modo de interpretar a realidade e a vida e a consequente prática que decorre dessa compreensão e que leva a uma ação transformadora (Freire, 2000, p. 38).

\section{Conclusão}

A análise das vivências de professoras em dois contextos nacionais distintos, tal como narradas por si, evidencia a influência e o impacto de políticas e discursos, transnacionais, de cunho marcadamente neoliberal e neocolonialista, no trabalho docente. Evidencia ainda o modo como o trabalho docente responde a demandas de qualidade que estão fora das escolas e do mundo das crianças e dos jovens em sua diferença e especificidade, subvertendo os fins democráticos e inclusivos que a educação escolar deve perseguir.

Tal como verificado noutros estudos, a narrativa é um tipo especial de discurso pois pode ser (re)contada e (re)interpretada. A narração da experiência vivida possibilita a (re)composição dos significados da experiência (incluindo aqueles aprendidos na atividade da escrita da narrativa), o que as leva a problematizar o sentido do trabalho docente e mesmo as suas identidades profissionais (Martins; Anunciato, 2018; Oliveira; Moreira, 2014; Viana, 2019).

Ao serem indagadas sobre a escrita das narrativas, as professoras entrevistadas reafirmam o seu potencial na promoção da reflexão, da reconstrução do pensamento, bem como da prática e da troca de experiências, que contribuem indelevelmente para o seu desenvolvimento pessoal e profissional. Todavia, também salientam as 
dificuldades sentidas, como a ausência de hábitos de reflexão escrita e de uma linguagem própria para essa tarefa, a falta de tempos e espaços para a escrita e para o diálogo profissional, o distanciamento do "eu" da realidade a ser analisada ou o assumir fragilidades e limitações num espaço partilhado e sujeito ao escrutínio de outros (Oliveira; Moreira, 2014).

Como nos recorda Vieira (2014, p. 15), quando os professores assumem o papel de investigadores da sua prática (como acontece com a produção das narrativas), a sua indagação desafia as forças históricas e estruturais que condicionam a transformação da educação ou, pelo contrário, ignoram ou aceitam essas forças, contribuindo para sua manutenção. A consciência dos obstáculos não impede que essas professoras lutem para transformar a realidade vivida; essa ação as situa num espaço indefinível entre o real e o ideal, um espaço de reflexão crítica sobre os interesses que (não) são servidos, "sem perder a esperança e a capacidade de resistência" (Vieira; Moreira, 2011, p. 62).

\section{Agradecimentos}

A primeira autora agradece o apoio pelo Centro de Investigação em Educação (CIEd), Instituto de Educação, Universidade do Minho, projetos UIDB/01661/2020 e UIDP/01661/2020, através de fundos nacionais da FCT/MCTES-PT.

A segunda autora agradece o apoio do Conselho Nacional de Desenvolvimento Científico e Tecnológico (CNPq) ao projeto "Diálogo intergeracional na indução de professores: o estabelecimento de um contínuo de formação docente" (Processo n ${ }^{\circ}$ 404133/2016-9).

A terceira autora também agradece o apoio do CNPq concedido ao projeto "Narrativas reflexivas de professores com necessidades especiais" (Processo n ${ }^{\circ}$ 2019/125658).

\section{Referências bibliográficas}

ADICHIE, C. N. O perigo de uma única história. In: TED GLOBAL 2009: the substance of things not seen, 2009, Oxford. Ted: ideas worth spreading. Oxford, 2009. Disponível em: < https://www.ted.com/talks/chimamanda_ngozi_adichie_ the_danger_of_a_single_story?language $=$ pt-br > . Acesso em: 21 out. 2020.

ANTUNES, F.; PERONI, V. Reformas do Estado e políticas públicas: trajetórias de democratização e privatização em educação: Brasil e Portugal, um diálogo entre pesquisas. Revista Portuguesa de Educação, Braga, v. 30, n. 1, p. 181-216, jun. 2017. Disponível em: <http://dx.doi.org/10.21814/rpe.7399>. Acesso em: 09 jun. 2020.

BARTOLOMÉ, L. I. Pedagogia da subordinação. Mangualde: Pedago, 2007. 
BOLÍVAR, A. Metodología de la investigación biográfico-narrativa: recogida y análisis de datos. In: PASSEGGI, M. C.; ABRAHÃO, M. H. M. B. (Orgs.). Dimensões epistemológicas e metodológicas da investigação (auto)biográfica. Porto Alegre: Editora da PUCRS, 2012. Tomo II, p. 79-109.

BRASIL. Lei no 10.639, de 9 de janeiro de 2003. Altera a Lei no 9.394, de 20 de dezembro de 1996, que estabelece as diretrizes e bases da educação nacional, para incluir no currículo oficial da Rede de Ensino a obrigatoriedade da temática "História e Cultura Afro-Brasileira", e dá outras providências. Diário Oficial da União, 10 jan. 2003. Seção 1, p. 1.

BRASIL. Ministério da Educação (MEC). Secretaria de Articulação com os Sistemas de Ensino (Sase). Planejando a próxima década: conhecendo as 20 metas do Plano Nacional De Educação. Brasília, DF: MEC, 2014.

BRAUN, V.; CLARKE, V. Using thematic analysis in psychology. Qualitative Research in Psychology, v. 3, n. 2, p. 77-101, 2006. Disponível em: < https://www. tandfonline.com/doi/abs/10.1191/1478088706qp063oa>. Acesso em: 5 fev. 2020.

CASA-NOVA, M. J. Os ciganos é que não querem integrar-se? In: SOEIRO, J; CARDINA, M.; SERRA, N. (Orgs.). Não acredite em tudo o que pensa: mitos do senso comum na era da austeridade. Lisboa: Tinta da China, 2013. p. 213-222.

CLANDININ, D. J.; CONNELLY, F. J. Pesquisa narrativa: experiência e história em pesquisa qualitativa. Uberlândia: Editora da UFU, 2011.

CONNELLY, F. M.; CLANDININ, D. J. Narrative inquiry. In: GREEN, J. L. et al. (Eds.). Handbook of complementary methods in education research. Washington D.C.: American Educational Research Association \& Lawrence Earlbaum Associates, 2006. p. 477-487.

COUNCIL OF EUROPE (CE). Commissioner for Human Rights. Human rights of Roma and travellers in Europe. Strasbourg: CE Publications, 2012.

DARDER, A. Cultura e poder na sala de aula: bases educativas para a escolarização de estudantes biculturais. Ramada: Pedago, 2015.

DELORY-MOMBERGER, C. Abordagens metodológicas na pesquisa biográfica. Revista Brasileira de Educação, Rio de Janeiro, v. 17, n. 51, p. 523-536, dez. 2012. Disponível em: <http://dx.doi.org/10.1590/S1413-24782012000300002>. Acesso em: 9 jun. 2020.

ESCUDERO, J. M.; TRILLO, F. Desenvolvimento profissional do professor: crise do currículo, das práticas e os efeitos da formação docente? In: FLORES, M. A.; MOREIRA, M. A.; OLIVEIRA, L. R. (Orgs.). Desafios curriculares e pedagógicos na formação de professores. Ramada: Pedago, 2017. p. 33-84.

EUROPEAN UNION AGENCY FOR FUNDAMENTAL RIGHTS (FRA). Fundamental rights report 2019. Luxembourg: FRA, 2019. Available in: <https://fra.europa.eu/ en/publication/2019/fundamental-rights-report-2019>. Access in: 21 Oct. 2020. 
FLICK, U. An introduction to qualitative research. London: Sage, 2009.

FRA ver European Union Agency for Fundamental Rights

FREIRE, P. A educação na cidade. São Paulo: Cortez, 1991.

FREIRE, P. Pedagogia da autonomia: saberes necessários à prática educativa. São Paulo: Paz e Terra, 2000.

KRASZEWSKA, K.; KNAUTH, B.; THOROGOOD, D. Indicators of immigrant integration: a pilot study. Luxembourg: Publications Office of the European Union, 2011. (Eurostat Methodologies \& Working papers). Available in: < https:// ec.europa.eu/eurostat/documents/3888793/5849845/KS-RA-11-009-EN.PDF. pdf/9dcc3b37-e3b6-4ce5-b910-b59348b7ee0c?t=1414780195000>. Access: 21 Oct. 2020.

LARROSA, J. Notas sobre narrativa e identidad: a modo de presentación. In: ABRAHÃO, M. H. M. B. (Org.). A aventura (auto)biográfica: teoria e empiria. Porto Alegre: Editora da PUCRS, 2004. p. 11-27.

MARTINS, R. M.; ANUNCIATO, R. M. M. Caminhos de aprendiz de professora: processos identitários em uma comunidade de aprendizagem online. Educação em Revista, Belo Horizonte, v. 34, e172625, jan. 2018. Disponível em: < http://dx.doi. org/10.1590/0102-4698172625>. Acesso em: 9 jun. 2020.

MIZUKAMI, M. G. N. A aprendizagem da docência: algumas contribuições de L. S. Shulman. Revista do Centro de Educação, Santa Maria, v. 29, n. 2, p. 3350, dez. 2004. Disponível em: <https://periodicos.ufsm.br/reveducacao/article/ view/3838>. Acesso em: 9 jun. 2020.

ORGANISATION FOR ECONOMIC CO-OPERATION AND DEVELOPMENT (OECD). Against the Odds: disadvantaged students who succeed in school. Paris: OECD Publishing, 2011. Disponível em: < https://doi.org/10.1787/9789264090873-en>. Acesso em: 09 jun. 2020.

OLIVEIRA, R. M. M. A.; MOREIRA, M. A. L. "Entre o amor e o ódio": narrativas de avaliação das aprendizagens em Portugal e no Brasil. Revista Teias, Rio de Janeiro, v. 15, n. 37, p. 13-28, set. 2014. Disponível em: <https://www.epublicacoes.uerj.br/index.php/revistateias/article/view/24418/17396> . Acesso em: 9 jun. 2020.

PARASKEVA, J. M. Nova teoria curricular. Lisboa: Edições Pedago, 2010.

PARASKEVA, J. A narrativa como contra-narrativa. In: MOREIRA, M. A. (Org.). Narrativas dialogadas na investigação, formação e supervisão de professores. Mangualde: Pedago, 2011. p. 7-21.

PARASKEVA, J. Curriculum epistemicide: toward an itinerant curriculum theory. New York: Routledge, 2016.

PERONI, V. M. V.; CAETANO, M. R.; ARELARO, L. R. G. BNCC: disputa pela qualidade ou submissão da educação? Revista Brasileira de Política e 
Administração da Educação, Brasília, v. 35, n. 1, p. 35-56, jan./abr. 2019. Disponível em: <https://doi.org/10.21573/vol1n12019.93094>. Acesso em: 9 jun. 2020

PORTUGAL. Comissão Nacional da Unesco. Objetivos de desenvolvimento sustentável. Lisboa, 2020. Disponível em: < https://unescoportugal.mne.gov.pt/pt/ temas/objetivos-de-desenvolvimento-sustentavel>. Acesso em: 21 out. 2020.

PORTUGAL. Direção Geral de Estatísticas de Educação e Ciência (DGEEC). Perfil escolar da comunidade cigana: 2016/17. Lisboa: DGEEC, 2017. Disponível em: <https://www.dgeec.mec.pt/np4/906.html>. Acesso em: 20 out. 2020.

QUIJANO, A. Colonialidad y modernidade/racionalidade. Perú Indígena, Lima, v. 13, n. 29, p. 11-20, 1992.

SANTOS, B. S. Para além do pensamento abissal: das linhas globais a uma ecologia de saberes. Novos Estudos CEBRAP, São Paulo, n. 79, p. 71-94, nov. 2007.

SANTOS, B. S. A filosofia à venda, a douta ignorância e a aposta de Pascal. Revista Crítica de Ciências Sociais, Coimbra, n. 80, p. 11-43, mar. 2008. Disponível em: https://www.ces.uc.pt/bss/documentos/A_filosofia_a_venda_RCCS80_Marco2008. pdf Acesso em: 9 jun. 2020.

TORRES SANTOMÉ, J. A desmotivação dos professores. Mangualde: Pedago, 2006

TORRES SANTOMÉ, J. La justicia curricular: el caballo de troya de la cultura escolar. Madrid: Morata, 2011.

TORRES SANTOMÉ, J. The intercultural curriculum: Networks and global communities for collaborative learning. In: PARASKEVA, J. M.; STEINBERG, S. R. (Eds.). Curriculum: decanonizing the field. New York: Peter Lang, 2016. p. 503-525.

VAZQUEZ-RECIO, R.; LOPÉZ-GIL, M. Interseccionalidad, jóvenes "sin-sistema" y resistência: una mirada diferente del fracaso/abandono escolar. Revista Brasileira de Educação, Rio de Janeiro, v. 23, e230094, 2018. Disponível em: < https://www. scielo.br/pdf/rbedu/v23/1809-449X-rbedu-23-e230094.pdf>. Acesso em: 9 jun. 2020 .

VIANA, M. A. Narrativas reflexivas de professores em formação, aprofundamento teórico. In: VIANA, M. A. (Org.). Narrativas dialogadas na formação de professores: experiências no PIBID e nos estágios supervisionados. Maceió: Centro de Educação, Universidade Federal de Alagoas, 2019. p. 21-36.

VIEIRA, F. Pedagogia, formação e investigação. In: VIEIRA, F. (Org). Quando os professores investigam a pedagogia: em busca de uma educação mais democrática. Mangualde: Pedago, 2014. p. 11-57.

VIEIRA, F. Pedagogy of experience in teacher education for learner and teacher autonomy. Profile Issues in Teachers' Professional Development, Bogotá, v. 22, n. 1, p. 143-158, Jan./June 2020. Disponível em: <https://revistas.unal.edu.co/ index.php/profile/article/view/78079>. Acesso em: 1 jul. 2020. 
VIEIRA, F.; MOREIRA, M. A. Supervisão e avaliação de desempenho docente: para uma abordagem de orientação transformadora. Lisboa: Ministério da Educação, CCAP, 2011.

WILSON, S.; SHULMAN, L. S.; RICHERT, A. E. 150 ways of knowing: representations of knowledge in teaching. In: CALDERHEAD, J. (Ed.). Exploring teachers' thinking. London: Cassell, 1987. p. 104-124.

Maria Alfredo Moreira, doutora em Ciências da Educação pela Universidade do Minho, Portugal, é professora auxiliar no Instituto de Educação da Universidade do Minho. Atua nas áreas da Formação de Professores (Supervisão Pedagógica, Narrativas Profissionais, Justiça Social) e Educação em Línguas Estrangeiras. Foi investigadora visitante na Universidade de Washington (EUA) e na Universidade de Cádiz (Espanha) e professora visitante na Universidade Federal de São Carlos (UFSCar) e em várias universidades europeias, nas quais desenvolveu atividade de ensino e de investigação centrada nas narrativas profissionais, formação de professores para a justiça social, insucesso escolar e investigação-ação crítica.

malfredo@ie.uminho.pt

Rosa Maria Moraes Anunciato, doutora em Educação pela Universidade Federal de São Carlos (UFSCar), é professora titular do Departamento de Teorias e Práticas Pedagógicas dessa universidade. Bolsista Produtividade em Pesquisa nível 2 do CNPq. Coordena o grupo de pesquisa Estudos sobre a Docência: Teorias e Práticas. Tem experiência na área de Educação, com ênfase em Formação de Professores, atuando principalmente nos seguintes temas: formação de professores, concepções sobre a docência, anos iniciais do ensino fundamental, narrativas de professores e aprendizagem profissional da docência.

rosa@ufscar.br

Maria Aparecida Pereira Viana, doutora em Educação: Currículo pela Pontifícia Universidade Católica de São Paulo (PUC-SP), com pós-doutoramento na Universidade do Minho, Portugal, é docente do Centro de Educação (Cedu) da Universidade Federal de Alagoas (Ufal), com atuação na graduação e pós-graduação (Especialização e Mestrado), membro do colegiado do curso de Pedagogia presencial e a distância, e, também, é membro da equipe do Programa Formação Continuada de Professores (Proford/Prograd/Progep/UFAL) na área Docência Universitária/TDIC. Colabora com o Centro para a Inovação e o Desenvolvimento do Ensino e da Aprendizagem (IDEA) da Universidade do Minho, Portugal.

maria.viana@cedu.ufal.br

Recebido em 10 de julho de 2020

Aprovado em $1^{\circ}$ de setembro de 2020 